\title{
Rafał Kosiński. « The Date of the Martyrdom of Simeon bar Sabba'e and the Persecution of Christians in Persia under Shapur II »
}

Christelle Jullien

\author{
(2) OpenEdition \\ Journals \\ Édition électronique \\ URL : http://journals.openedition.org/abstractairanica/50932 \\ DOI : 10.4000/abstractairanica. 50932 \\ ISBN : 1961-960X \\ ISSN : 1961-960X \\ Éditeur : \\ CNRS (UMR 7528 Mondes iraniens et indiens), Éditions de l'IFRI
}

\section{Référence électronique}

Christelle Jullien, «Rafał Kosiński. «The Date of the Martyrdom of Simeon bar Sabba'e and the Persecution of Christians in Persia under Shapur II » », Abstracta Iranica [En ligne], Volume 40-41 | 2019, document 12, mis en ligne le 30 décembre 2019, consulté le 25 avril 2021. URL : http:// journals.openedition.org/abstractairanica/50932; DOI : https://doi.org/10.4000/abstractairanica. 50932

Ce document a été généré automatiquement le 25 avril 2021.

Tous droits réservés 


\title{
Rafał Kosiński. «The Date of the Martyrdom of Simeon bar Sabba'e and the Persecution of Christians in Persia under Shapur II »
}

\author{
Christelle Jullien
}

\section{RÉFÉRENCE}

Rafał Kosiński. « The Date of the Martyrdom of Simeon bar Sabba'e and the Persecution of Christians in Persia under Shapur II ", Zeitschrift für Antikes Christentum / Journal of Ancient Christianity 21/3, 2017, p. 496-519

1 Ce compte rendu concerne également la référence suivante (la version polonaise de l'article) : Rafał Kosiński, «Once again on the Date of the Martyrdom of Simeon bar Sabba'e and the Persecution of Christians in Persia under Shapur II ", Zeszyty Naukowe Uniwersytetu Jagiellońskiego, Prace Historyczne 144/1, 2017, p. 1-24 [en polonais].

2 Depuis les travaux ciblés de M. J. Higgins dans Traditio (1955), R. W. Burgess dans les Analecta Bollandiana (1999), et récemment la thèse de K. Smith publiée chez Gorgias Press en 2014, cet article, publié la même année en anglais et en polonais, reprend à nouveaux frais la question de la date du martyre de Siméon Bar Șabba'ê, primat de Séleucie-Ctésiphon au milieu du IV ${ }^{\text {e }}$ siècle, et donc de la date du déclenchement de la politique d'hostilité de Šābuhr II envers la minorité chrétienne. Il rappelle que les sources réexaminées donnent clairement le début $d u V^{e} s$. et le règne de Yazdgird $I$ comme époque où commencèrent à être mis par écrit les actes des martyrs perses, écartant définitivement l'attribution de la collection martyrologique à Maroutha de Mayperqat à la suite d'autres chercheurs notamment Ph. Wood (The Chronicle of Seert). Ce dernier avait proposé à titre d'hypothèse le nom de l'évêque de Karkā d-Ledān Șaumaï, mentionné dans la passion de Jacques le notaire, initiateur d'un culte des 
reliques au profit de son église de Susiane où se trouvaient déjà les restes de Siméon (voir aussi dans la passion de Bar Șabba'ē). L’église de Perse alors en pleine expansion aurait cherché à valoriser les souffrances par la communauté chrétienne ; pour cette raison, la collection consacrée aux martyrs du IV siècle devait recevoir sa forme définitive au cours des deux siècles suivants comme une expression de l'identité naissante de l'Église d'Orient.

3 L'A. effectue un minutieux état de la recherche, montrant les différentes hypothèses avancées jusqu'alors et défend la thèse qu'il n'est pas possible de déterminer avec précision la date du décès de Siméon compte tenu notamment du genre hagiographique des sources relatant son martyre - qu'il situe dans une fouchette comprise entre février 344 et juillet 345 , probablement fin 344 . Il souscrit à la thèse selon laquelle le 'grand massacre' suivit le martyre Siméon, qui en constitua le premier acte, ce que confirme la Chronique de Séert. Il tient par ailleurs pour probable que la date de promulgation de l'édit royal aurait été préservée dans les sources restituées par la Chronique d'Arbèles. Pour l'A., même si l'idée d'un édit ordonnant la destruction des églises n'est pas nécessairement pure invention hagiographique comme le proposait K. Smith, l'importance de la perspective symbolique pourrait expliquer un remaniement des dates par le narrateur : édit paru la $31^{\mathrm{e}}$ année de Šābuhr pour déterminer une période de 40 ans à partir de la mort de Siméon, nombre d'années qui renvoie à la période exodique de purification du peuple hébreu dans le désert ; à la communauté affaiblie (ce dont Aphraate se fait l'écho) répondrait alors la restauration et la restructuration (lors du synode de 410) de l'Église de Perse. Ce procédé d'écriture serait pour lui un indice que le texte du Martyre aurait été rédigé durant la période de paix du tournant $\mathrm{du} \mathrm{V}^{\mathrm{e}}$ siècle, époque où se déroula l'assemblée synodale. L'A. ne tient pas compte des travaux de R. Payne (2015) remettant en question l'idée d'une persécution globale des chrétiens à cette époque.

\section{AUTEURS}

\section{CHRISTELLE JULLIEN}

CNRS, Mondes iranien et indien, Paris 